\title{
Correspondence
}

\section{Congenital nephrogenic diabetes insipidus}

Sir,

Schreiner and co-workers reported a baby girl with congenital nephrogenic diabetes insipidus (NDI) (Archives, 1978, 53, 906). I should like to contribute a case diagnosed as having partial NDI.

This boy had been transferred from a local hospital at age 9 months because of high fever with high serum $\mathrm{Na}$ and $\mathrm{C} 1$ concentrations, initially noticed in the first week of life. His mother showed polydipsia and polyuria: her urine osmolality after water deprivation for 12 hours was $270 \mathrm{mmol} / \mathrm{kg}$. Investigation of the patient showed high serum osmolality $(315 \mathrm{mmol} / \mathrm{kg})$, low urine osmolality (100 mmol $/ \mathrm{kg}$ ), serum $\mathrm{Na} 172 \mathrm{mmol} / \mathrm{l}$, and serum C1 $126 \mathrm{mmol} / \mathrm{l}$.

Subsequently clearance studies were performed while the boy was receiving both a normal and a salt-restricted diet, after water deprivation, and after intravenous DDAVP (Aronson and Svenningsen, 1974). The main results were: (1) On water deprivation the patient was able to concentrate urine up to $600 \mathrm{mmol} / \mathrm{kg}$ simultaneously with reduction of urine volume; after DDAVP $(0.4 \mathrm{ml} \mathrm{IV})$ urine volume decreased further; osmolar clearance, which had increased during water deprivation, decreased after DDAVP. (2) On normal diet and on salt-restricted diet DDAVP resulted in increasing osmolar and free water clearance (and urine volume).

We made the following interpretations on the effect of DDAVP (a synthetic vasopressin analogue) on our patient's kidneys: renal resistance to DDAVP was incomplete; there was an adequate response after giving DDAVP during water deprivation, whereas a paradoxical effect on osmolar and free water clearance (Brodehl et al., 1965) was apparent during the control periods.

Partial NDI (McConnell et al., 1977) was diagnosed and treated by salt restriction and frusemide $(15 \mathrm{mg} /$ day $)$. Follow-up 3 years later shows uncomplicated physical and psychological development of the patient with normal or almost normal values for serum $\mathrm{Na}, \mathrm{C1}$, urea nitrogen, osmolality, and bicarbonate. Urine osmolality ranged from 200 to $265 \mathrm{mmol} / \mathrm{kg}$.

I wonder if Schreiner and co-workers would like to comment on our patient, particularly with regard to their own therapeutic experience.

\section{References}

Aronson, A. S., and Svenningsen, N. W. (1974). DDAVP test for estimation of renal concentrating capacity in infants and children. Archives of Disease in Childhood, 49, 654-659.

Brodehl, J., Gellissen, K., and Hagge, W. (1965). Die Wirkung des Vasopressins beim Diabetes insipidus renalis. Klinische Wochenschrift, 43, 72-78.
McConnell, R. F., Jr, Lorentz, W. B., Jr, Berger, M., Smith, E. H., Carvajal, H. F., and Travis, L. B. (1977). The mechanism of urinary concentration in nephrogenic diabetes insipidus. Pediatric Research, 11, 33-36.

\section{P. KOEPP \\ Universitätskinderkinik, Martinistrasse 52, \\ D-2000 Hamburg 20, W. Germany}

\section{Myotonic dystrophy and bonding failure}

Sir,

In their report of 5 cases of the neonatal form of dystrophia myotonica (Archives, 1979, 54, 331), Pearse and Höweler emphasise the ethical problems facing the clinician once the diagnosis has been made, and they discuss the need for genetic counselling. We should like to add support to their concern for earlier diagnosis by drawing attention to another important and potentially lethal hazard run by babies with this condition-that is bonding failure. If they survive the neonatal period, these babies must always be considered to be at increased risk of rejection and neglect. Not only are they likely to have accumulated a number of the features commonly associated with child abuse-for example, neonatal separation, early ill health, maternal physical and emotional illness (Lynch, 1975; Lynch and Roberts, 1977) - but both mother and child are further handicapped by the inability to use facial expression effectively as a means of communication.

This was well illustrated by a family referred to the Park Hospital in Oxford. The parents were both very young and came from unhappy and divided homes, thus the potential for abuse was high. The mother's relationship with her own mother was hostile yet dependent, and the father had experienced a rigid authoritarian upbringing. When we met the mother she was just 20 and had had two caesarean sections within 13 months. Her second son had been very ill in the neonatal period, spending the first 7 weeks of his life in the special care baby unit. He had required assisted ventilation for some days. During his stay in the unit the diagnosis of myotonic dystrophy was made both in himself and his mother. A distaff family history of dystrophia myotonica was discovered, with the mother's own mother, the grandmother, and a great aunt suffering from cataracts and facial diplegia. It was also found that the elder brother had a milder form of the disease.

When finally discharged home, the baby had a floppy, expressionless face; he made none of the grimaces and little noises a normal baby makes. His abnormal cry was quiet and ineffective; his smile did not appear. Feeding was a nightmare. Much of his time he slept 'like a dead 
baby', making him easy to 'forget' and his mother was terrified that he would die silently without her noticing. She was at a further disadvantage by her own inability to use facial expression as a means of communication with her baby. Soon all those concerned in the baby's care, including the mother herself, were fearful for the baby's safety and help was sought before there was serious neglect or abuse.

The family were then admitted to the Park Hospital for an intensive period of treatment where the mother learned to make appropriate signals and respond to her baby. Both mother and child could gaze fixate, even though it could not be coupled with smiling. Starting from this, the mother was helped to recognise the more subtle signs from the baby, such as tiny mouth movements and slight panting sounds in her presence. The baby, too, was encouraged in making chuckling noises in response to his mother's gaze. Marital therapy was also required and it was interesting to note that in the mother's family all the sufferers of myotonic dystrophy had had broken marriages. Several years later, this family remains united but the parents still require help from both health and social services in bringing up their 2 young handicapped children.

\section{References}

Lynch, M. A. (1975). Ill-health and child abuse. Lancet, 2, 317-319.

Lynch, M. A., and Roberts, J. (1977). Predicting child abuse: signs of bonding failure in the maternity hospital. British Medical Journal, 1, 624-626.

MARGARET A. LYNCH Department of Paediatrics, Guy's Hospital, London SEI 9RT

JACQUELINE ROBERTS AND CHRISTOPHER OUNSTED Park Hospital for Children, Oxford

\section{Early use of sodium nitroprusside in respiratory distress syndrome}

Sir,

Beverley et al. (Archives, 1979, 54, 403) reported the response to sodium nitroprusside in an infant with hyaline membrane disease, and I should like to make some comments on their patient.

The course of the illness, with the infant not requiring added oxygen and only very low ventilator pressure by 24 hours of age, must cast doubt on the diagnosis of surfacant-deficiant hyaline membrane disease, and suggests that the baby was suffering from the after effects of severe birth asphyxia, the early problems of intrapartum pneumonia, or perhaps from some iatrogenic disease.

During the time sodium nitroprusside was being infused, 3 other major changes in treatment took place which may have been responsible for improving the baby's condition. Firstly, his $\mathrm{pH}$ was corrected. The effect of this on pulmonary perfusion and pulmonary vascular tone is well known, and could itself be responsible for the improved oxygenation in the infant. Secondly, the inspiratory to expiratory ratio was reduced from $4: 1$ to 1.5:1 and while we do not know the ventilator pressures that were sustained during this period, it seems likely that this would be associated with a considerable fall in the mean airways pressure. Particularly in infants without hyaline membrane disease, a high mean airways pressure can be responsible for serious pulmonary underperfusion, and lowering the airways pressure as was done in this patient, can be associated with a large increase in arterial $\mathrm{Po}_{2}$. Thirdly, they transfused their patient, and while we are given no blood pressure data before this was started, the fact that they were able to increase the baby's blood volume by more than double suggests that, irrespective of the hypotension-producing effect of the nitroprusside, the infant was previously hypovolaemic or hypotensive, or both. Correction of that could also be responsible for an improvement in the infant's condition and oxygenation.

I would submit therefore that Beverley et al. have provided absolutely no evidence for a beneficial effect from sodium nitroprusside in their patient, and that before this comparatively dangerous drug is used, evidence that it improves oxygenation while other factors in the treatment are held constant is required. This, for example, has been provided for tolazoline (McIntosh and Walters, 1979).

\section{Reference}

McIntosh, N., and Walters, R. O. (1979). Effect of tolazoline in severe hyaline membrane disease. Archives of Disease in Childhood, 54, 105-110.

\section{N. R. C. ROBERTON Department of Paediatrics, Addenbrooke's Hospital, Hills Road, Cambridge CB2 $2 Q Q$}

Sir,

The letter from Beverley et al. (Archives, 1979, 54, 403), and the report by Abbott et al. (1978) to which they refer, should both be treated with extreme caution. In neither is a good case made for the use of sodium nitroprusside to reduce pulmonary vascular resistance (PVR) in severely hypoxic newborn babies. While Beverley and colleagues refer to the known hazards of this hitherto untried drug, they give no details of the state of the circulation or of the $\mathrm{PaCO}_{2}$ during their infant's first few hours. These are important since poor tissue oxygenation and hypercapnia may both contribute to acidosis, and PVR in the newborn may be expected to increase as pH falls (Rudolph, 1977). The extreme acidosis at 2-4 hours of age was presumably the legacy of severe birth asphyxia.

Nevertheless, the information provided suggests that after a blood transfusion (which should have improved tissue oxygenation) and during the slow correction of the severe acidosis, there was initially a steady fall in right-toleft shunt, followed at the age of 11 hours by a more rapid improvement in both the arterial $\mathbf{p H}$ and $\mathrm{PaCO}_{2}$. 